\title{
Review and Evaluation of Protection Issues and Solutions for Future Distribution Networks
}

\author{
Md Asif Uddin Khan*, Qiteng Hong, Adam Dyśko and Campbell Booth \\ Department of Electronic and Electrical Engineering \\ University of Strathclyde \\ Glasgow, United Kingdom \\ *Email: asif.u.khan@strath.ac.uk
}

\begin{abstract}
This paper presents a comprehensive review and detailed investigation of the protection issues that may potentially arise due to the proliferation of technologies such as distributed generator (DG) and energy storage in future power distribution networks. A summary and critical evaluation of several potential protection and control solutions (applicable to the generators or the network), which are proposed as addressing one or more of the identified issues, are also presented. The analysis covers both economic and technological viability and feasibility. Finally, a mapping of the identified issues to the most appropriate proposed solutions is presented, along with discussion, analysis and conclusions.
\end{abstract}

Index Terms-Future distribution network, distributed generators (DGs), protection issues and solution schemes.

\section{INTRODUCTION}

Control, operation and performance of future distribution networks largely depend upon proper and effective selection and design of protection schemes, as this assists in ensuring the reliability and stability of the power supply and the safety of equipment, personnel and the public. Presently adopted protection schemes are designed to operate in the context of a strong power system, typically using large scale synchronous machines for the generation of electrical power.

However, the trend is changing to accommodate renewable and environment-friendly solutions and it is widely accepted that future power distribution systems will behave very differently from traditional systems due to the integration of huge amounts of small-scale generation units (using renewable sources), connected at the distribution level, commonly known as distributed generators (DGs). While this has many benefits [1]-[4], it can also introduce several challenges for protection. Reference [5] discuss various issues arising from increased penetration of DGs in the UK power networks. Reduced system inertia, increased rates of change of frequency (RoCoF) following disturbances, problems associated with frequency control and containment, voltage management and risks of instability are some of the issues investigated and reported by others.

Two of the most concerning elements associated with the increased use of renewables (both large and small scale) and with DGs are the relative reduction of overall shortcircuit level (SCL) and bidirectional current flow in the network. One of the major reasons behind the reduction of SCL is the use of power electronics-based inverters for interfacing of renewables, energy storage (which may contribute to fault current) in the distribution level and, at the transmission level, for interconnection with other power systems and with major renewable generation installations (e.g. offshore wind farms). These sources cannot provide the same SCL as the rotating conventional synchronous generators (which will reduce significantly in number and capacity in the near future in the UK) can provide.

This paper, through a review of relevant literature, will identify and analyse in detail the issues that will be encountered in future power distribution networks due to the addition of different technologies, and will also discuss various protection schemes with their positive and negative aspects as well as their practicality and feasibility. The paper is structured as follows: a review of future protection issues is presented in section II, section III presents proposed solutions for future application, section IV contains a table outlining the capabilities of the reviewed protection solutions to address the protection challenges and section $\mathrm{V}$ concludes the paper.

\section{REVIEW of Future Protection Issues}

The protection issues in future distribution networks can be classified into two main categories. The first category is related to the loss of coordination and issues with settings and responses across the various protection relays, reclosers and fuses during grid-connected operation. The second category relates to loss of mains (LOM) protection. Several protection issues with relays, reclosers and fuses are addressed by different researchers. A number of these issues, with illustrative examples, are presented in the following sections.

\section{A. Selectivity and Sensitivity issues due to Bi-directional Current Flow}

The protection of conventional distribution network is designed based on the assumption that the network has an unidirectional power flow during both normal and fault conditions [6]. However, the presence of DGs can result in bidirectional flows under certain circumstances. Conventional overcurrent-based protection does not possess directional current properties or features [6]. Therefore, current opposite to the direction of regular flow that is high enough in magnitude may cause a trip and opening of the corresponding circuit breaker (CB) although there is no fault on the downstream line, which seriously hampers the selectivity and characteristic of the protection scheme. In Fig. 1, there is potential for relays 
R1 and/or R4 to mal-operate due to reverse flow of current for the fault on the adjacent circuit resulting in unnecessary interruption to loads (i.e. Load 3).

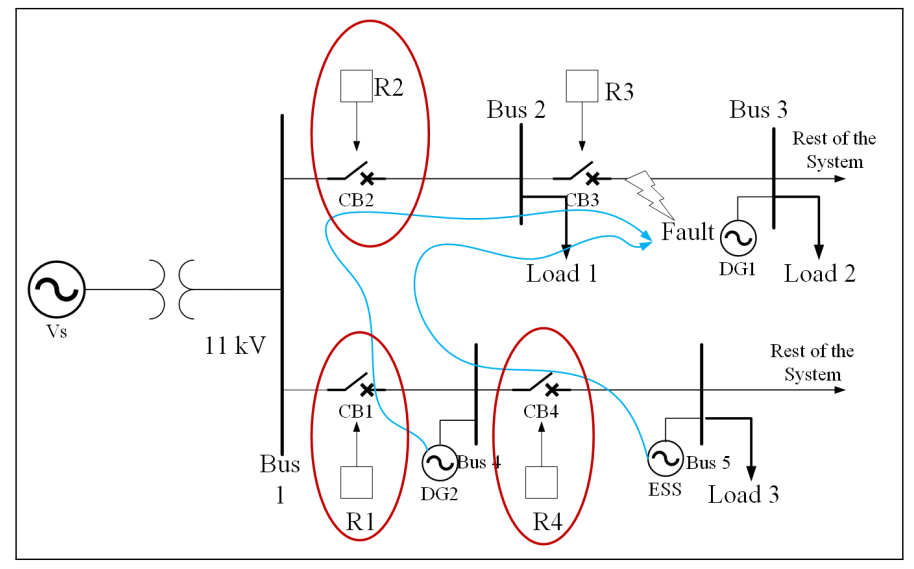

Fig. 1. Example of a distribution network with relays' mal-operation.

\section{B. Sympathetic Tripping of the Back-up Protection}

Reference [7] discusses the issue of sympathetic tripping of backup or secondary protection before primary protection operation. The settings of the overcurrent relays (OCR) are calculated through the fault current levels of the network and generally remain constant during the operation of the distribution network. However, due to additional fault currents supplied by DGs during grid connected mode of operation, the existing protection with fixed settings can operate faster than it should which may lead to sympathetic tripping of back-up protection. For example, in Fig. 1, relay R2 provides back-up for R3. Thus, R3 should operate faster than R2 for any fault between bus 2 and 3 but this expected behaviour deviates due to instantaneous element of the OCR, R2, which can be observed in Fig. 2. The green cross on the figure indicates operating time without DG, while the red cross indicates the operating time and fault current with DG connected to the network. So, from Fig. 2 it can be seen that for a fault between bus 2 and 3, R2 with red crossed operating point may operate faster (almost instantaneously) than R3 although R2 was backup.

\section{Nuisance Tripping of Undervoltage Protection}

According to settings policy/guidelines document G59/3 [9], the undervoltage protection of DG in the distribution network shall trip after $0.5 \mathrm{~s}$ if the measured network voltage at the DG location is less than $80 \%$ of nominal. [10] presents a simulated scenario with IDMT overcurrent relays and shows that the traditional protection system took a long time to operate than it should (more than $0.5 \mathrm{~s}$ ) due to the coordination intervals between the primary and back-up relays. As a result, the undervoltage protection of the DG is activated unnecessarily.

\section{Loss of Main (LOM) Protection}

Islanding scenarios can be divided into two categories, one is intentional islanding and the other is unintentional

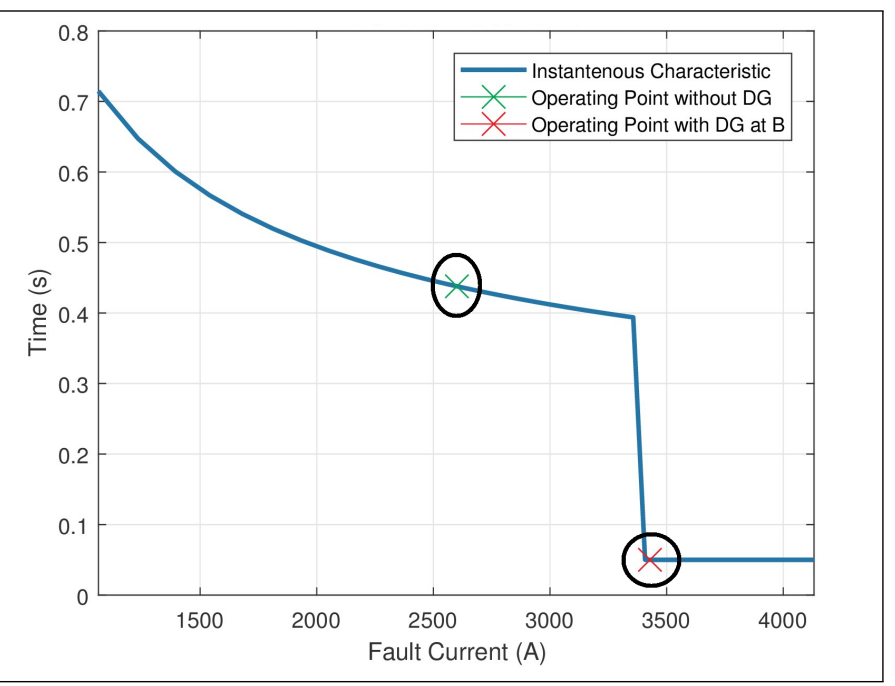

Fig. 2. Instantaneous protection characteristic showing with and without DG fault current contribution [8].

islanding. The definition unintentional islanding and LOM is provided in [11] and can take place in the network when DGs in the islanded network continue to supply electricity to the local loads and protection systems of the DGs do not identify the islanded condition. Various problems can take place and risks may be introduced within the network during unintentional islanding [12]. Some of the issues are listed here.

- Damage of the connected loads due to electromechanical torques generated by DGs.

- Creation of transient over-voltage surge on the feeder.

- Risk of life for the maintenance crews during maintenance.

Intentional islanding is achieved in a controlled fashion and is often proposed as being used in micro-grid systems which typically can operate in either grid-connected or islanded modes where the local generation has enough capacity to provide energy to supply the demand. However, a number of prerequisite conditions must be met before implementation of intentional islanding can be considered [13]. For examples(1) DGs must be capable of maintaining the standard limit of voltage and frequency in the network, (2) stability must be achieved, (3) the protection system of the islanded network must be able to detect and isolate the faults through the system.

\section{E. Out-of-Phase Auto-Reclose Issues}

During the deadtime in the reclosers operating sequence (i.e. when the recloser is open) in the islanded condition, there is a chance of developing a different phased voltage across the open terminals of recloser and causes out-ofphase reclosing, which could eventually cause damage to the network infrastructure [19]. Furthermore, during the deadtime, the deionised arc may actually be ionised by the sustaining arc from DGs, which could cause a temporary fault to become permanent [20]. 


\section{F. Recloser and Fuse Coordination Issues}

There are two types of techniques to coordinate reclosers and fuses in distribution networks: fuse sacrificing and fuse saving. Fuse saving is the most widely used technique in practice [21]. Reclosers clear temporary faults by tripping relatively faster than fuses (i.e. than the time at which fuse will blow), in the fuse saving mode [21]. However, placement of DG (e.g. between the recloser location and the fuse, for a fault downstream of the fuse), could act to increase fault current (or cause fault current to persist) for a fault beyond the fuse, resulting in fuse blowing, and potentially resulting in slower recloser operation due to reduced upstream fault current. These coordination problems are discussed further in [22], [23].

\section{Review of Proposed Solutions}

It can be understood from the above discussion that, under certain circumstances, traditional overcurrent protection scheme for distribution network may no longer suitable or sufficient for future applications. To mitigate and address protection issues, several solutions have been proposed by different researchers. This section of the paper outlines and analyses various protection solutions from the appropriate

TABLE I

Review and Critical Evaluation of Proposed Protective Solutions: Adaptive Protection Schemes

\begin{tabular}{ll}
\hline $\begin{array}{l}\text { Referenced } \\
\text { Article }\end{array}$ & Description of the Method \\
\hline & $\begin{array}{l}\text { This protection has the properties to automatically } \\
\text { change the settings of the overcurrent relays to incor- } \\
\text { porate the impact of DGs, Active Network Manage- } \\
\text { ment (ANM) and islanding operation. The scheme uses }\end{array}$ \\
& $\begin{array}{l}\text { IEC61850 enabled devices to communicate between the } \\
\text { upstream and downstream (primary and back-up) relays } \\
\text { so that coordination between them can be achieved. }\end{array}$
\end{tabular}

It is an adaptive overcurrent scheme validated by the hardware-in-the-loop (HIL) simulations. Several setting groups for the relays are determined through a real-time calculation of fault current contribution from differen sources. Then, the optimal setting groups are achieved through the optimisation of primary and secondary relays' coordination.

Uses local measurement to adopt the settings of the OC relays. To detect the islanded condition voltage and [15] frequency of the systems are measured and two settings are proposed one for grid connection and another one is for islanded operation.

Divided the distribution network into several zones, each having separate DGs and loads for islanded operation. Zones are connected to each other through breakers. The frequency of the system load for each zone is control by the largest DGs. The method includes offline calculation of short-circuit current and power-flow to modify the protection settings. Detection of fault is achieved through continuous comparison of the total currents in the network with the total contribution of currents from the sources in the normal condition.

The scheme modifies the TMS of IDMT characteristic for reclosers and fuses. It measures the fault current ratio between reclosers and fuse. If the ratio is less than 1 , the TMS is multiplied with the ratio of the recloser and fuse current.

The method involves modification of settings for multistage definite time (DT) overcurrent relays for the underground distribution network using local measurements. The adaptive approach is achieved through real-time calculation of the Thevenin equivalent parameters.
Positive Impacts

The scheme addresses the ANM and its contribution to fault levels and fault current paths. Proper coordination between relays is possible along with monitoring and control of the distribution network.

Addressing DG impact on the distribution network, it is possible to achieve coordination between the relays. The optimization model is robust and capable of calculating more accurate setting groups for overcurrent relay. Also, solved the problem of offline operation issue.

The proposed scheme is relatively simple and suitable for the operation of the islanded operation with limited DGs. A comparison between the contribution of currents from the transmission grid and DGs in islanded operation has been made.

The paper discussed the relays settings along with its coordination with CBs. Also, the recloser-fuse coordination for temporary faults is addressed.

The method was tested in the DG connected distribution network through PSCAD simulations and performance during high impedance single phase fault was satisfactory and able to maintain the coordination between the recloser and fuse.

The scheme is relatively economical as it uses the local measurements instead of synchronised phasor measurements. The coordination between the back-up and primary protection of the OC relays are achieved and selectivity \& sensitivity issues of the protection are also addressed.

\section{Shortcomings}

It requires communication links and additional Intelligent Electronic Devices, which is costly. Also, in the algorithm, it does not mention how much variation should change the protection parameters and settings. The paper did not mention anything about the offline calculation and operation of the proposed scheme.

Apart from communication links between the relays and the central controller, several other intelligent electronic devices and directional overcurrent relays are required for this scheme. Thus, the scheme is too expensive.

The scheme only discusses the islanded operation but the coordination problems due to DGs during gridconnected mode are not addressed. Also, only one setting can limit the DGs operation in the islanded mode.

The capacity of the DGs in each zone is assumed to be constant (higher than the connected load). The offline calculations needed to be run with each addition of DGs and load variations. The algorithm for locating faults is complex and does not appear efficient.

The scheme does not involve the OC relay and recloser or fuse coordination. The scheme was tested only for one scenario of the DG connected distribution network.

The efficiency and accuracy of the scheme are not good as local measurements are used to calculate the parameters. The optimisation process requires lots of rigorous calculation and if the network size increases, the scheme might not work properly. 
literature. The schemes are classified into three categories. The first two categories are covered using brief descriptions, supplemented with summary tables (as there are many proposed solutions), while the third category is described in the main text of the paper.

\section{A. Adaptive Protection Schemes}

Adaptive schemes are the most popular and widely researched form of flexible protective solution. According to the definition, the scheme can change various protection settings, such as the Plug Settings (PS) and Time Multiple Settings (TMS) in overcurrent relays, according to the prevailing fault levels in the network [29]. A short summary of reviews of different available adaptive protection schemes from different literature is presented in Table I.

\section{B. New Protection Schemes}

To acknowledge future distribution network protection requirements, various studies suggest novel protection methods that replace conventional overcurrent schemes. Specifically, inverter-interfaced source/storage typically does not produce significantly large currents when faults occur close to them due to their rated capacity [6]. This typical limit of fault currents may not be sufficient to activate IDMT overcurrent relays. Various types of protection schemes are suggested, including protection based on voltage measurement, harmonic content, travelling waves, etc. Each produces different techniques to locate and identify the faults. A summary of the novel schemes for distribution line protection is listed in Table. II with critical evaluation included.

\section{Managing Fault Contribution from DGs}

As synchronous based DGs may typically contribute fault currents more than 5 to 6 times of the rated output current [6], the motivation of this approach is to limit the fault current contribution from the DGs during grid connected mode of operation so that the original coordination settings of the preinstalled overcurrent relays do not need to change. This is not normally necessary for small DGs or DGs interfaced via power electronics inverters.

Reference [30] introduces the technique of Fault Current Limiters (FCL) in the radial distribution system. Low impedance is maintained by the FCL during normal operating condition but during a fault, it increases the impedance value to a level that can limit DG fault current contribution to almost zero. The method removes the complexity of changing or

TABLE II

Review and Critical Evaluation of Proposed Protective Solutions: New Protection Schemes

\begin{tabular}{lll}
\hline $\begin{array}{l}\text { Referenced } \\
\text { Article }\end{array}$ & Description of the Method & Positive Impacts \\
\hline & & $\begin{array}{l}\text { The method is extremely efficient } \\
\text { in detecting the internal fault within }\end{array}$ \\
the bus and external high impedance \\
fault. In terms of reliability the \\
scheme has high precision of achieve- \\
ment and the scheme also very cost \\
(DWT) to achieve the direction and location of the fault \\
in terms of agent-based protection. The algorithm of \\
the agent-based protection is implemented through the \\
simulation of the distribution network in the PSCAD.
\end{tabular}

This method aims to detect the islanding, based on the principle of the rate of change of power, calculated from a pre-set value of power and continuous measurements of voltages and currents. Then, the moving average with a window of $120 \mathrm{~ms}$ of $50 \mathrm{~Hz}$ system is measured and compared with pre-set protection settings.
The scheme is capable of remain stable during harmonic interferences and relatively simple to implement.
The scheme monitors the voltage at islanded or microgrid systems and uses d-q transformation to convert the ac (abc phase voltage) quantity into dc (static d-q frame) quantity. Then the static d-q frame is converted to the synchronous rotating frame. During the faults, the dq value deviates from nominal values.

\section{Shortcomings}

The islanded operation is not feasible through the scheme and largely depends upon the communication link between the agents. Though the paper considered the scheme to be an economical solution, it uses the DWT filter and communication system with each of the relay agents which is not very cost effective for distribution networks.

The change of load and intermittent power sources can vary the power flow and as a result, the rate of change of power might activate the protection algorithm unnecessarily.

Do not provide protection against the

Can be used in the grid-connected mode and islanded operation.

The method is suitable for the protection of the networks with inverter based DGs. The scheme also can provide back-up protection with proper coordination with the other relays. high impedance faults (HIFs) and sensitive to voltage condition. So, change grid voltage during load variations can activate the systems protection.

Not applicable for the grid-connected mode. Also, might not work properly with different types of DGs with different fault level contributions.
Based on travelling wave method two algorithms are proposed. The first algorithm is a disturbance classification algorithm and the other one is a fault location algorithm. The fault location algorithm detects the internal and external fault based on a comparison between fault generated travelling wave energy and threshold energy value (determined through fault type and inception angle).
The proposed algorithm only requires local measurements and does not require communication channels. Thus, it is less expensive. Also, the scheme can provide protection against HIFs.
Impact of power converter based DGs and energy storage are not addressed or examined in the scheme. Also, the variation of DGs fault contribution might create problems. 
modifying the protection settings along with control of the DGs operation during the fault conditions. As a result, the connection of FCLs can provide flexibility on the control operation of DGs and centralised monitoring unit. However, the scheme has serious issues associated with losses, size, reliability, operation speed and cost.

A fuzzy logic decision-making module is designed in [31] to monitor the DGs contribution in the network and modify the penetration level of DGs during the fault. Also, a digital numerical algorithm is developed through fast recursive discrete Fourier transformation to control the operation of DGs. The scheme has both control and adaptive protection functions, but the algorithm is very complex and difficult to implement in practice.

Reference [32] suggested an approach where location, size and penetration level of DGs are optimised through the measurement of Protection Coordination Index (PCI). PCI is the ratio between the change of penetration power in the distribution network by DGs and change in the coordination time interval. However, limiting the DGs capacity is not desirable during intentional islanding operation.

\section{Suitability of Proposed Solutions}

The protection schemes suggested by different researchers definitely have a number of advantages in terms of mitigating DG impacts on the distribution network. However, section III has also provided insight relating to certain limitations of the protection/control schemes and it is clear that some schemes may not be able to address all protection challenges. Thus, Table. III summarises the protection schemes, issues and each schemes requirements through mapping them so that a better understanding of various schemes capabilities can be provided, leading to development of future protection schemes that can be more flexible, cost-effective and capable of addressing a wider range of issues more effectively.

The ratings provided in Table. III (beside the referenced article) for each scheme is based on the performance of that scheme and are of course, somewhat subjective. The criteria of this rating are based on- addressing the stated protection issues, practical applications in the real world, complexity of the algorithm and cost. The rating has three divisions: H- High performance, M- Medium performance and L- Low performance. This rating is provided according to the points

TABLE III

MAPPING OF PRoposed SCHEMES AND PROTECTION ISSUES

\begin{tabular}{|c|c|c|c|c|c|c|c|c|c|}
\hline \multirow{2}{*}{$\begin{array}{l}\text { Protection } \\
\text { Schemes }\end{array}$} & \multirow{2}{*}{$\begin{array}{l}\text { Referenced } \\
\text { Articles \& } \\
\text { Rating }\end{array}$} & \multicolumn{5}{|c|}{ Protection Issues } & \multicolumn{3}{|c|}{ Additional Requirements and feasibility } \\
\hline & & $\begin{array}{c}\text { Sensitivity } \\
\& \\
\text { selectivity }\end{array}$ & $\begin{array}{l}\text { Coordination } \\
\text { with back-up }\end{array}$ & Operating time & $\begin{array}{c}\text { HIFs } \\
\text { detection }\end{array}$ & $\begin{array}{l}\text { Islanded } \\
\text { operation }\end{array}$ & Communication & Cost & Complexity \\
\hline \multirow{6}{*}{ 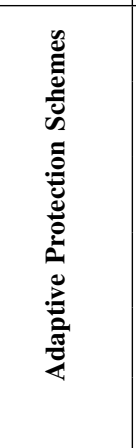 } & {$[10](\mathrm{L})$} & High & Possible & $\begin{array}{l}\text { Depends on } \\
\text { communication }\end{array}$ & $\begin{array}{c}\text { Not } \\
\text { possible }\end{array}$ & Possible & Required & Expensive & Simple \\
\hline & {$[14](\mathrm{L})$} & High & Possible & $\begin{array}{l}\text { Depends on } \\
\text { communication }\end{array}$ & $\begin{array}{c}\text { Not } \\
\text { possible }\end{array}$ & Possible & Required & Expensive & Simple \\
\hline & [15] (M) & High & Not possible & Relatively fast & $\begin{array}{c}\text { Not } \\
\text { possible }\end{array}$ & possible & Not required & Moderate & Simple \\
\hline & {$[16](\mathrm{L})$} & High & Possible & $\begin{array}{l}\text { Depends on } \\
\text { communication }\end{array}$ & $\begin{array}{c}\text { Not } \\
\text { possible }\end{array}$ & Possible & Required & Expensive & Complex \\
\hline & {$[17](\mathrm{L})$} & Low & Not Possible & $\begin{array}{l}\text { Depends on } \\
\text { current }\end{array}$ & $\begin{array}{c}\text { Not } \\
\text { Possible }\end{array}$ & $\begin{array}{c}\text { Not } \\
\text { Possible }\end{array}$ & Not required & cheap & Simple \\
\hline & {$[18](\mathrm{M})$} & High & Possible & $\begin{array}{l}\text { Depends on } \\
\text { impedance }\end{array}$ & $\begin{array}{c}\text { Not } \\
\text { possible }\end{array}$ & $\begin{array}{c}\text { Not } \\
\text { possible }\end{array}$ & Not required & cheap & Complex \\
\hline \multirow{5}{*}{ 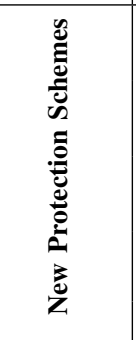 } & [24] (L) & High & Possible & $\begin{array}{l}\text { Depends on } \\
\text { communication }\end{array}$ & $\begin{array}{c}\text { Not } \\
\text { possible }\end{array}$ & $\begin{array}{c}\text { Not } \\
\text { possible }\end{array}$ & Required & Expensive & Complex \\
\hline & [25] (L) & Low & Not possible & Fast & $\begin{array}{c}\text { Not } \\
\text { possible }\end{array}$ & Possible & Required & Expensive & Simple \\
\hline & [26] (H) & Low & Possible & Fast & $\begin{array}{c}\text { Not } \\
\text { possible }\end{array}$ & Possible & Not required & $\begin{array}{l}\text { Relatively } \\
\text { cheap }\end{array}$ & Simple \\
\hline & [27] (M) & Low & Possible & Slow & $\begin{array}{c}\text { Not } \\
\text { Possible }\end{array}$ & Possible & Not required & Moderate & Simple \\
\hline & [28] (M) & High & Possible & Slow & Possible & Possible & Not required & Expensive & Complex \\
\hline \multirow{4}{*}{ 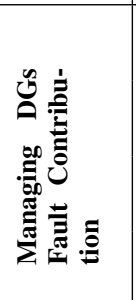 } & {$[30](\mathrm{L})$} & High & Not possible & $\begin{array}{l}\text { Depends on } \\
\text { current }\end{array}$ & $\begin{array}{c}\text { Not } \\
\text { possible }\end{array}$ & $\begin{array}{c}\text { Not } \\
\text { possible }\end{array}$ & Not required & Expensive & Simple \\
\hline & [23] (M) & Low & Possible & $\begin{array}{c}\text { Depends on } \\
\text { voltage at PCC }\end{array}$ & $\begin{array}{c}\text { Not } \\
\text { possible }\end{array}$ & Possible & Not required & $\begin{array}{l}\text { Relatively } \\
\text { cheap }\end{array}$ & Simple \\
\hline & [31] (L) & High & Possible & Fast & $\begin{array}{c}\text { Not } \\
\text { possible }\end{array}$ & Possible & Required & Expensive & Complex \\
\hline & [32] (M) & Low & Possible & $\begin{array}{c}\text { Depends on } \\
\text { PCI }\end{array}$ & $\begin{array}{c}\text { Not } \\
\text { possible }\end{array}$ & $\begin{array}{c}\text { Not } \\
\text { possible }\end{array}$ & Required & Expensive & Simple \\
\hline
\end{tabular}


(0-10) the scheme has scored. Appropriately meeting the criteria of protection issues will score 5 points (one point for each issues) and rest of the points will be based on the other features (communication: 1, cost: 2 and complexity: 2). The achieved score of (0-4) indicates-L, (5-7) indicates-M and (8-10) indicates-H.

\section{Conclusions}

The paper outlines various protection-related challenges and issues in future distribution networks that may arise due to the addition of renewable energy based DGs. A review of a number of protection and control schemes proposed by other researchers was then presented, along with a mapping of the proposed solutions to the identified issues.

In conclusion. the paper has shown that there is no single comprehensive and practical solution to all of the potential future issues and there remains a significant requirement for research towards developing and demonstrating a protection/control scheme to address future issues in distribution system operating in both grid connected and islanded modes.

\section{REFERENCES}

[1] M. Triggianese, F. Liccardo, and P. Marino, "Ancillary services performed by distributed generation in grid integration," in 2007 International Conference on Clean Electrical Power, May 2007, pp. 164-170.

[2] J. He, M. S. Munir, and Y. W. Li, "Opportunities for power quality improvement through dg-grid interfacing converters," in The 2010 International Power Electronics Conference - ECCE ASIA -, June 2010, pp. 1657-1664.

[3] F. Coffele, C. Booth, and G. Burt, "Detailed analysis of the impact of distributed generation and active network management on network protection system," in The 21st International Conference on Electricity Distribution, June 2011.

[4] J. He, Y. W. Li, and M. S. Munir, "A flexible harmonic control approach through voltage-controlled dggrid interfacing converters," IEEE Transactions on Industrial Electronics, vol. 59, no. 1, pp. 444-455, Jan 2012.

[5] National Grid, "System operability framework 2016," November 2016. [Online]. Available: https://www.nationalgrideso.com/document/63481/ download

[6] V. Telukunta, J. Pradhan, A. Agrawal, M. Singh, and S. G. Srivani, "Protection challenges under bulk penetration of renewable energy resources in power systems: A review," CSEE Journal of Power and Energy Systems, vol. 3, no. 4, pp. 365-379, Dec 2017.

[7] A. Girgis and S. Brahma, "Effect of distributed generation on protective device coordination in distribution system," in LESCOPE 01. 2001 Large Engineering Systems Conference on Power Engineering. Conference Proceedings. Theme: Powering Beyond 2001 (Cat. No.01ex490), July 2001, pp. 115-119.

[8] M. A. U. Khan and C. D. Booth, "Detailed analysis of the future distribution network protection issues," The Journal of Engineering, vol. 2018, no. 15, pp. 1150-1154, 2018.

[9] Energy Networks Association (ENA), "Recommendations for the connection of generating plant to the distribution systems of licensed distribution network operators," 2018.

[10] F. Coffele, C. Booth, and A. Dyko, "An adaptive overcurrent protection scheme for distribution networks," IEEE Transactions on Power Delivery, vol. 30, no. 2, pp. 561-568, April 2015.

[11] D. M. Laverty, R. J. Best, and D. J. Morrow, "Loss-of-mains protection system by application of phasor measurement unit technology with experimentally assessed threshold settings," IET Generation, Transmission Distribution, vol. 9, no. 2, pp. 146-153, 2015.

[12] "Ieee application guide for ieee std $1547(\mathrm{tm})$, ieee standard for interconnecting distributed resources with electric power systems," IEEE Std 1547.2-2008, pp. 1-217, April 2009.

[13] F. Pilo, G. Celli, and S. Mocci, "Improvement of reliability in active networks with intentional islanding," in 2004 IEEE International Conference on Electric Utility Deregulation, Restructuring and Power Technologies. Proceedings, vol. 2, April 2004, pp. 474-479 Vol.2.
[14] V. A. Papaspiliotopoulos, G. N. Korres, V. A. Kleftakis, and N. D. Hatziargyriou, "Hardware-in-the-loop design and optimal setting of adaptive protection schemes for distribution systems with distributed generation," IEEE Transactions on Power Delivery, vol. 32, no. 1, pp. 393-400, Feb 2017.

[15] P. Mahat, Z. Chen, B. Bak-Jensen, and C. L. Bak, "A simple adaptive overcurrent protection of distribution systems with distributed generation," IEEE Transactions on Smart Grid, vol. 2, no. 3, pp. 428-437, Sep. 2011.

[16] S. M. Brahma and A. A. Girgis, "Development of adaptive protection scheme for distribution systems with high penetration of distributed generation," IEEE Transactions on Power Delivery, vol. 19, no. 1, pp. 56-63, Jan 2004.

[17] P. H. Shah and B. R. Bhalja, "New adaptive digital relaying scheme to tackle recloser-fuse miscoordination during distributed generation interconnections," IET Generation, Transmission Distribution, vol. 8, no. 4, pp. 682-688, April 2014.

[18] S. Shen, D. Lin, H. Wang, P. Hu, K. Jiang, D. Lin, and B. He, "An adaptive protection scheme for distribution systems with dgs based on optimized thevenin equivalent parameters estimation," IEEE Transactions on Power Delivery, vol. 32, no. 1, pp. 411-419, Feb 2017.

[19] J. Kennedy, P. Ciufo, and A. Agalgaonkar, "A review of protection systems for distribution networks embedded with renewable generation," Renewable and Sustainable Energy Reviews, vol. 58, pp. 1308 - 1317, 2016. [Online]. Available: http://www.sciencedirect.com/science/article/pii/S136403211501641X

[20] L. K. Kumpulainen and K. T. Kauhaniemi, "Analysis of the impact of distributed generation on automatic reclosing," in IEEE PES Power Systems Conference and Exposition, 2004., Oct 2004, pp. 603-608 vol.1.

[21] A. R. Haron, A. Mohamed, and H. Shareef, "A review on protection schemes and coordination techniques in microgrid system," Journal of Applied Sciences, vol. 12, pp. 101-112, 022012.

[22] S. Chaitusaney and A. Yokoyama, "Prevention of reliability degradation from recloserfuse miscoordination due to distributed generation," IEEE Transactions on Power Delivery, vol. 23, no. 4, pp. 2545-2554, Oct 2008.

[23] H. Yazdanpanahi, Y. W. Li, and W. Xu, "A new control strategy to mitigate the impact of inverter-based dgs on protection system," IEEE Transactions on Smart Grid, vol. 3, no. 3, pp. 1427-1436, Sep. 2012.

[24] N. Perera and A. D. Rajapakse, "Agent-based protection scheme for distribution networks with distributed generators," in 2006 IEEE Power Engineering Society General Meeting, June 2006, pp. 6 pp.-.

[25] M. A. Redfern, J. I. Barrett, and O. Usta, "A new loss of grid protection based on power measurements," in Sixth International Conference on Developments in Power System Protection (Conf. Publ. No. 434), March 1997, pp. 91-94.

[26] H. Al-Nasseri, M. A. Redfern, and F. Li, "A voltage based protection for micro-grids containing power electronic converters," in 2006 IEEE Power Engineering Society General Meeting, June 2006, pp. 7 pp.-.

[27] H. Al-Nasseri and M. A. Redfern, "Harmonics content based protection scheme for micro-grids dominated by solid state converters," in 2008 12th International Middle-East Power System Conference, March 2008, pp. 50-56.

[28] N. Davydova and G. Hug, "Travelling wave protection with disturbance classification for distribution grids with distributed generation," The Journal of Engineering, vol. 2018, no. 15, pp. 830-835, 2018.

[29] A. G. Phadke, M. Ibrahim, and T. Hlibka, "Fundamental basis for distance relaying with symmetrical components," IEEE Transactions on Power Apparatus and Systems, vol. 96, no. 2, pp. 635-646, March 1977.

[30] W. El-Khattam and T. S. Sidhu, "Restoration of directional overcurrent relay coordination in distributed generation systems utilizing fault current limiter," IEEE Transactions on Power Delivery, vol. 23, no. 2, pp. 576-585, April 2008.

[31] D. S. Kumar, D. Srinivasan, and T. Reindl, "A fast and scalable protection scheme for distribution networks with distributed generation," IEEE Transactions on Power Delivery, vol. 31, no. 1, pp. 67-75, Feb 2016.

[32] H. H. Zeineldin, Y. A. I. Mohamed, V. Khadkikar, and V. R. Pandi, "A protection coordination index for evaluating distributed generation impacts on protection for meshed distribution systems," IEEE Transactions on Smart Grid, vol. 4, no. 3, pp. 1523-1532, Sep. 2013. 